ISSN 1996-1944

www.mdpi.com/journal/materials

Article

\title{
Fabrication of Cellulose ZnO Hybrid Nanocomposite and Its Strain Sensing Behavior
}

\author{
Hyun-U Ko ${ }^{1}$, Seongcheol Mun ${ }^{1}$, Seung-Ki Min ${ }^{1}$, Gi-Woo Kim ${ }^{2}$ and Jaehwan Kim ${ }^{1, *}$
}

1 Department of Mechanical Engineering, Inha University, Incheon 402-751, Korea;

E-Mails: lostmago@naver.com (H.-UK.); bobtf@hanmail.net (S.M.); msg8398@ nate.com (S.-K.M.)

2 School of Automotive Engineering, Kyungpook National University, 386 Gajangdong, Sangju, Kyungsangpook-Do 742-711, Korea; E-Mail: gwkim2@knu.ac.kr

* Author to whom correspondence should be addressed; E-Mail: jaehwan@inha.ac.kr; Tel.: +82-32-860-7326; Fax: +82-32-832-7325.

External Editor: Klara Hernadi

Received: 7 August 2014; in revised form: 8 October 2014 / Accepted: 9 October 2014 / Published: 16 October 2014

\begin{abstract}
This paper reports a hybrid nanocomposite of well-aligned zinc oxide ( $\mathrm{ZnO})$ nanorods on cellulose and its strain sensing behavior. $\mathrm{ZnO}$ nanorods are chemically grown on a cellulose film by using a hydrothermal process, termed as cellulose $\mathrm{ZnO}$ hybrid nanocomposite (CEZOHN). CEZOHN is made by seeding and growing of $\mathrm{ZnO}$ on the cellulose and its structural properties are investigated. The well-aligned $\mathrm{ZnO}$ nanorods in conjunction with the cellulose film shows enhancement of its electromechanical property. Strain sensing behaviors of the nanocomposite are tested in bending and longitudinal stretching modes and the CEZOHN strain sensors exhibit linear responses.
\end{abstract}

Keywords: cellulose; zinc oxide; piezoelectric; nanocomposite; strain sensor

\section{Introduction}

Cellulose is a cheap and renewable biopolymer in the world, traditionally used for paper, pulp and textiles. In recent years, cellulose has been rediscovered as a smart material that can be used for sensors, actuators and electronics [1]. The electromechanical behavior of so-called electro-active paper (EAPap) has been reported and electromechanical devices, such as physical sensor, speaker, bending 
actuator have been demonstrated [2-4]. Besides, electrochemical and electrical devices based on cellulose hybrid composites have also been reported, such as gas sensor, $\mathrm{pH}$ sensor, biosensor, and field effect transistor [5-8].

Zinc oxide $(\mathrm{ZnO})$ is a well known nanomaterial. Because of its wide band gap $(3.47 \mathrm{eV})$ and high hole-electron biding energy $(60 \mathrm{meV})$, great attention is paid to it for semiconductors, photo-catalytic devices, gas sensors, photovoltaics and piezoelectric energy harvesters [9-11]. Furthermore, since $\mathrm{ZnO}$ is biocompatible, it is useful for biomedical applications [12]. Micro energy harvesting devices is also a great issue of this material. Nanoscale mechanical energy can be converted into electrical energy by means of piezoelectric $\mathrm{ZnO}$ nanowire arrays [13]. On the other hands, composite materials of $\mathrm{ZnO}$ and organic material are very promising for flexible devices [10,11]. To fabricate the organic- $\mathrm{ZnO}$ composite material, suitable organic substrate is important. Because cellulose is a renewable material, it can be a great candidate for the organic substrate of $\mathrm{ZnO}$ hybrid composite. Some research efforts have been given for growing $\mathrm{ZnO}$ nanostructure on cellulose. A $\mathrm{ZnO}$ nanowire based solar cell was made on a flexible paper by sputtering $\mathrm{ZnO}$ [14]. ZnO strain sensor was made on cellulose substrate by hydrothermal method [15]. However, they only used cellulose paper as a flexible substrate. Since paper has randomly oriented cellulose fibers, the paper surface is so rough that its sensing performance could be low.

In this paper, we report a fabrication of well-aligned $\mathrm{ZnO}$ nanorods on cellulose and its strain sensing behavior. To maintain good alignment of $\mathrm{ZnO}$ nanorods, a regenerated cellulose film was used, on which smooth surface is possessed, and a hydrothermal process was adopted with seeding and growing steps of $\mathrm{ZnO}$. The fabricated CEZOHN is tested for its strain sensing behaviors under bending and longitudinal stretching modes.

\section{Experimental Section}

\subsection{Materials}

Cotton pulp with degree of polymerization (DP), 4500 was purchased from Buckeye Technology, and $\mathrm{N} / \mathrm{N}$-Dimethylacetamide (DMAc), zinc nitrate $\left(\mathrm{Zn}\left(\mathrm{NO}_{3}\right)_{2}\right)$, zinc sulfate $\left(\mathrm{ZnSO}_{4}\right)$, triethanolamine (TEA) and ammonium chloride $\left(\mathrm{NH}_{4} \mathrm{Cl}\right)$ were purchased from Sigma-Aldrich.

\subsection{Fabrication}

At first, cellulose film was fabricated by dissolving cotton pulp and regenerating it. Detailed process was previously reported $[2,4]$ and this is a brief summary. The pulp was dissolved by mixing it with DMAc and $\mathrm{LiCl}$ mixture at $150{ }^{\circ} \mathrm{C}$ with stirring. The cellulose solution was cast on a glass using a doctor blade, followed by putting into a mixture of deionized (DI) water and isopropyl alcohol. And then, a wet cellulose film can be obtained.

$\mathrm{ZnO}$ nanorods were grown on the wet cellulose film by using a hydrothermal process. Figure 1 shows the schematic of $\mathrm{ZnO}$ growing process divided into seeding and growing. To produce uniform $\mathrm{ZnO}$ nanorods, seeding process was added before $\mathrm{ZnO}$ nanorods growing. The wet cellulose film was fixed on a glass and it was loaded in $1000 \mathrm{~mL}$ DI water at $80{ }^{\circ} \mathrm{C} .25 \mathrm{mM} \mathrm{Zn}\left(\mathrm{NO}_{3}\right)_{2}$ and TEA were added to the DI water with stirring for $250 \mathrm{rpm}$. The aqueous solution was stirred and kept at $80{ }^{\circ} \mathrm{C}$ for 
$6 \mathrm{~h}$. After seeding, the cellulose was washed with DI water to remove unfixed $\mathrm{ZnO}$ particles and kept in DI water. To grow $\mathrm{ZnO}$ nanorods, an aqueous solution of $\mathrm{ZnSO}_{4}$ and $\mathrm{NH}_{4} \mathrm{Cl}$ was prepared by adding $15 \mathrm{mM}$ of $\mathrm{ZnSO}_{4}$ and $450 \mathrm{mM}$ of $\mathrm{NH}_{4} \mathrm{Cl}$ in $500 \mathrm{~mL}$ DI water at $60{ }^{\circ} \mathrm{C}$. pH of the solution was controlled to 11.5 with $\mathrm{NaOH}$ to lead the deposition of $\mathrm{ZnO}$ [16]. The seeded cellulose was loaded in the solution and remained for $6 \mathrm{~h}$ at $60{ }^{\circ} \mathrm{C}$. After growing, the $\mathrm{ZnO}$ grown cellulose was washed and dried over $6 \mathrm{~h}$ in an ambient condition.

Figure 1. Schematic of CEZOHN (cellulose $\mathrm{ZnO}$ hybrid nanocomposite) fabrication process: seeding and growing of $\mathrm{ZnO}$.
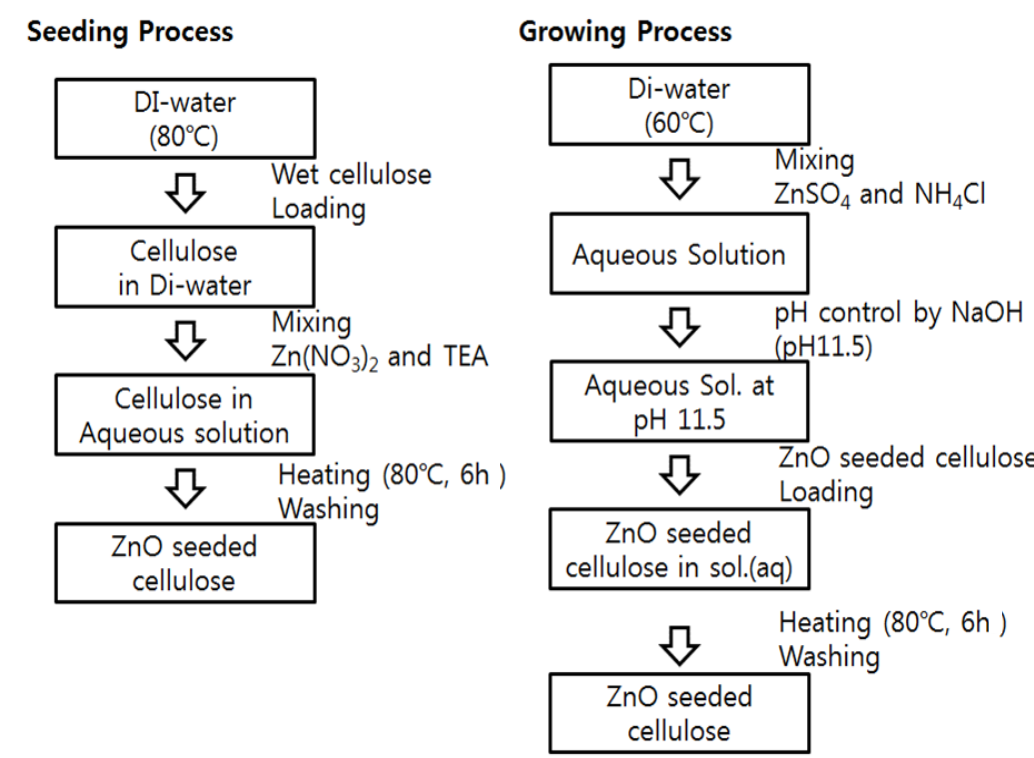

\subsection{Characterization}

Morphology of cellulose $\mathrm{ZnO}$ was observed by scanning electron microscope (SEM, S-4000, 4300, Hitachi, Tokyo, Japan). X-ray diffraction spectrum has been obtained using XRD (Rigaku, Tokyo, Japan) by using is $\mathrm{Cu}-\mathrm{Ka} 1$ at $40 \mathrm{kV}, 100 \mathrm{~mA}$. FT-IR spectrum (Varian Excalibur FTS 3000, Walnut Creek, $\mathrm{CA}$, USA) was used to analyze the interaction between cellulose and $\mathrm{ZnO}$.

\subsection{Strain Sensor Test}

Before investigation of strain sensor, piezoelectric charge constant and Young's modulus was measured by a quasi-static method [2]. The performance of strain senor was tested with bending mode and longitudinal stretching mode. Figure 2 shows the experimental setup of strain sensor for bending and stretching modes. To investigate the strain sensor, aluminum electrode was coated on outsides of cellulose and $\mathrm{ZnO}$ layer. The strain sensor was electrically insulated by laminating it with a film. For bending mode test, as shown in Figure $2 \mathrm{a}$, the strain sensor was attached on one side of a fixed aluminum bar $\left(300 \times 50 \times 2 \mathrm{~mm}^{3}\right)$ and tipped at the free end of the bar. Displacement at the free end was measured by a laser displacement sensor (Keyance LK-G85, Tokyo, Japan) and the displacement signal and the generated signal from the attached strain sensor were fed to the pulse signal analyzer. For stretching mode test, the pull test equipment was used as shown in Figure 2b [2]. The strain sensor was fixed between two grippers of the pull test machine and pulling displacement can be precisely 
controlled. When the strain sensor was pulled, then its displacement and force were monitored from the equipment and induced charge of the strain sensor was measured by using a picoammeter (Keithly 6485, Cleveland, OH, USA). The pulling speed was set to $0.5 \mu \mathrm{m} / \mathrm{s}$ for the quasi-static condition.

Figure 2. Experimental setup of strain sensor for (a) bending mode and (b) stretching mode.
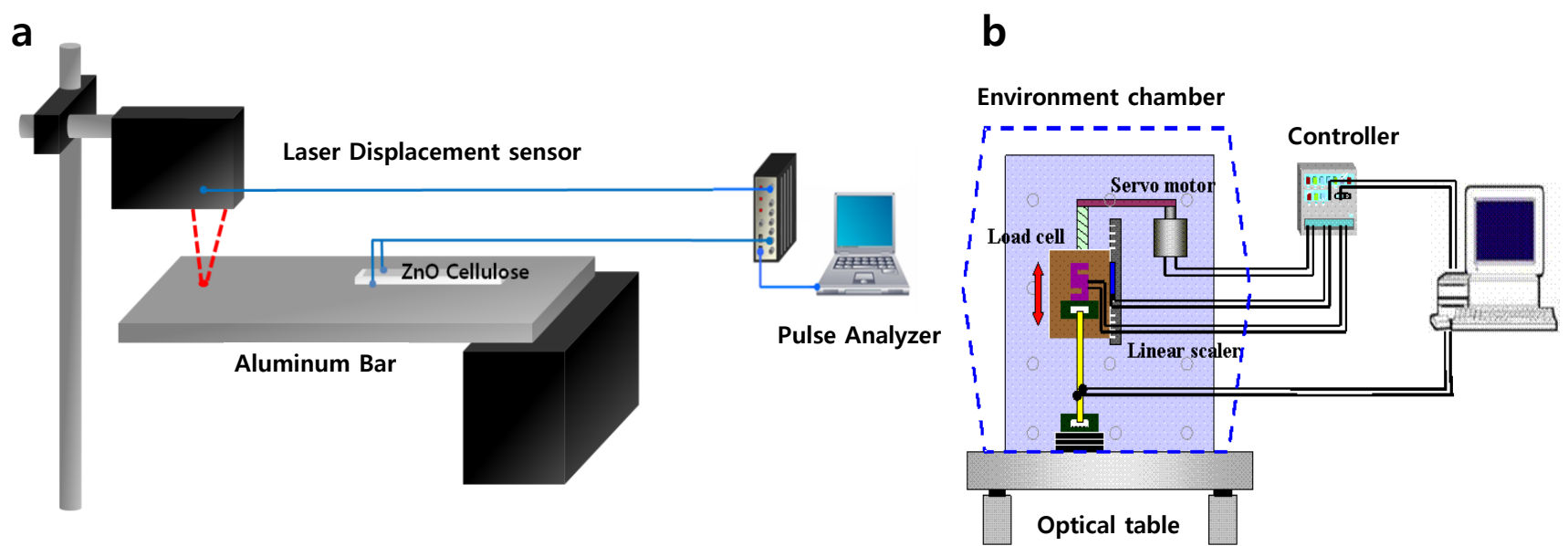

\section{Results and Discussion}

\subsection{ZnO Nanorod Growth on Cellulose}

Before growing $\mathrm{ZnO}$ nanorods, the hydrothermal process was conducted without seeding. Figure 3 shows surface and cross sectional SEM images of $\mathrm{ZnO}$ nanorods grown on the cellulose film. The cellulose has smooth surface and after the growing $\mathrm{ZnO}$, rod like particles and octahedral $\mathrm{ZnO}$ particles fully covered the cellulose surface. In the EDS result, particles are found to be $\mathrm{ZnO}$ and/or $\mathrm{ZnOH}$. Octahedral structure of $\mathrm{ZnO}$ demonstrates that $\mathrm{OH}$ of $\mathrm{Zn}(\mathrm{OH})_{2}$ is not perfectly removed by the thermal hydrolysis reaction [16]. To increase the uniformity of $\mathrm{ZnO}$ nanorods, additional process is required.

Figure 3. SEM images of CEZOHN without seeding at (a) surface and (b) cross section.
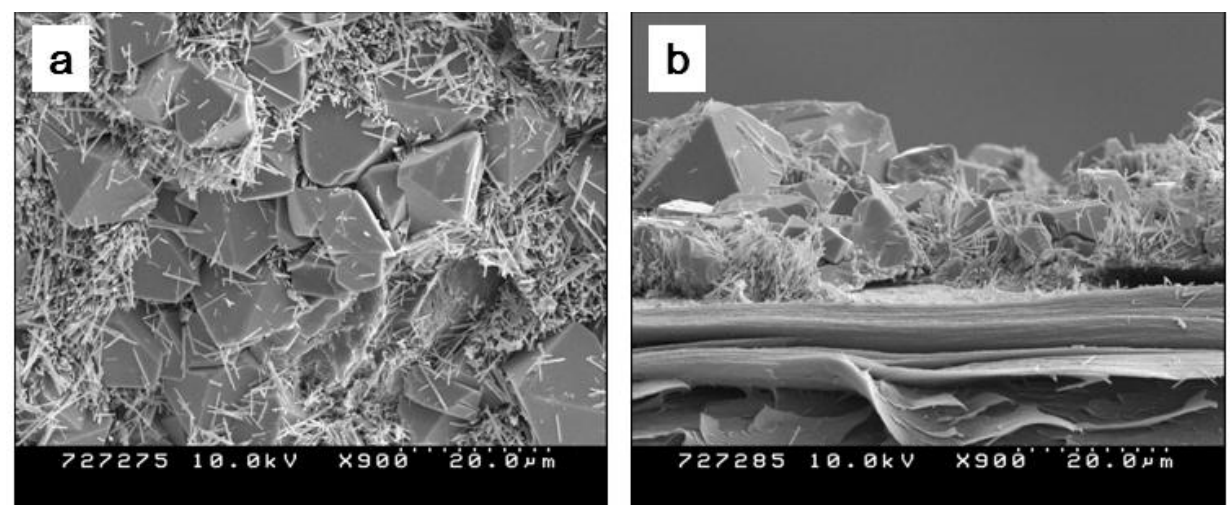

To uniformly grow $\mathrm{ZnO}$ nanorods on the cellulose film, a seeding process was added with the hydrothermal reaction before $\mathrm{ZnO}$ nanorod growing. Figure $4 \mathrm{a}$ shows the SEM image of $\mathrm{ZnO}$ seed layer. The seed layer is composed of 0-demention $\mathrm{ZnO}$ spheres. Diameter of $\mathrm{ZnO}$ seeds is around $250 \mathrm{~nm}$. ZnO rods are grown on the seed layer by hydrothermal process. Figure $4 \mathrm{~b}$ shows the surface 
SEM image of the $\mathrm{ZnO}$ nanorods after growing. Diameter of $\mathrm{ZnO}$ is similar to $\mathrm{ZnO}$ spheres of the seed layer. Figure 4d shows the cross-sectional SEM image of the $\mathrm{ZnO}$ nanorods grown on the cellulose film. Figure 4c shows EDS result, which can confirm that $\mathrm{ZnO}$ particles are formed.

Figure 4. SEM images of CEZOHN with seeding and growing processes: (a) seed layer; (b) surface; (c) EDX and (d) cross section.
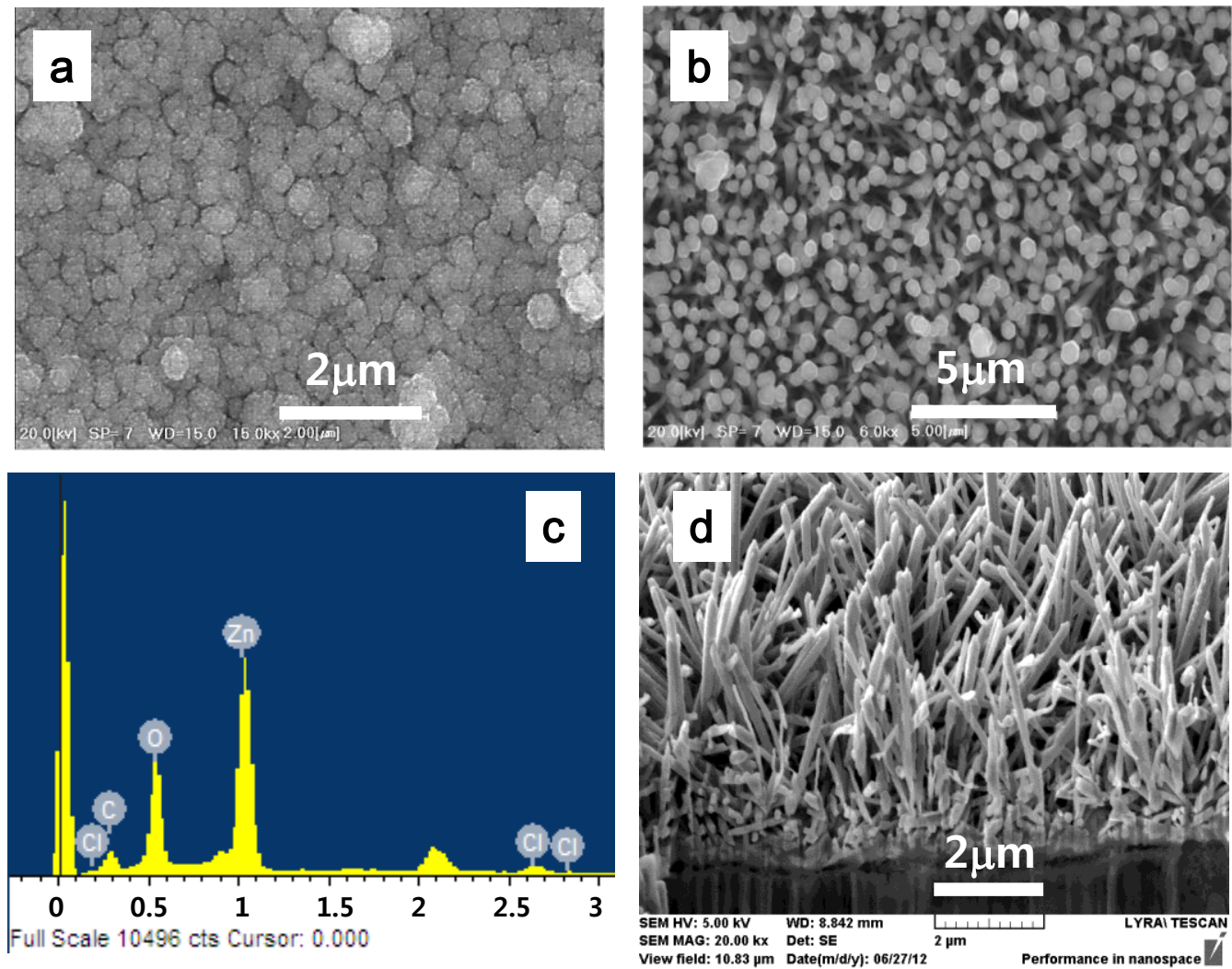

Figure 5a shows the XRD pattern of CEZOHN. Characteristic peak of cellulose appeared broadly at $2 \theta=20.9^{\circ}$ and narrow peaks at $31.7^{\circ}, 34.4^{\circ}, 36.2^{\circ}$ are assigned to (100), (002) and (101), which shows Wurtzite structure of $\mathrm{ZnO}$. Dominant (002) peak indicates that $\mathrm{ZnO}$ rods are well aligned perpendicularly, which is shown in Figure 4d. FT-IR spectrum of cellulose and CEZOHN is shown in Figure 5b. At the cellulose spectrum, the broad band of $\mathrm{OH}$ functional group is observed at $3365 \mathrm{~cm}^{-1}$. The characteristic band of $\mathrm{C}-\mathrm{C}$ with benzene ring at $1627 \mathrm{~cm}^{-1}$ and the $\mathrm{C}-\mathrm{H}$ vibrations at $2912 \mathrm{~cm}^{-1}$ can be attributed the cellulose. Although characteristic band of $\mathrm{ZnO}$ is almost covered with cellulose characteristic band in the spectra of CEZOHN, the spectra demonstrate intensity reduction of functional bands of cellulose suggesting that hydroxyl groups are occupied with $\mathrm{ZnO}$. In other words, $\mathrm{ZnO}$ is physically interacting to cellulose chains. 
Figure 5. (a) XRD result and (b) FTIR result of CEZOHN and cellulose.

a

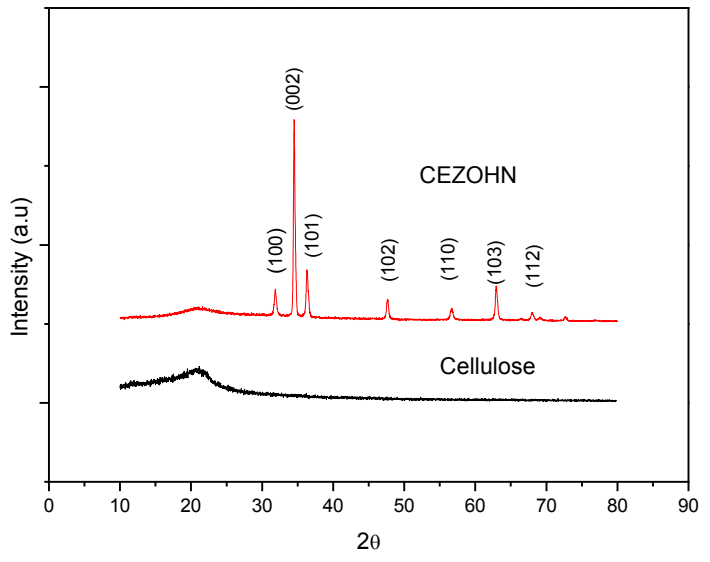

b

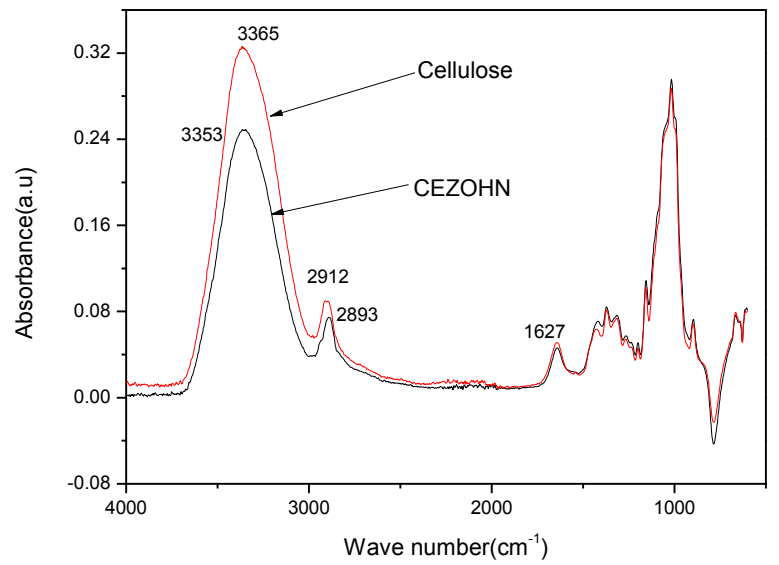

\subsection{Physical Properties}

To investigate potential of piezoelectric devices, mechanical properties and electromechanical properties of CEZOHN were measured by the quasi-static method. Figure 6 shows the stress-strain curve and induced charge curve. Table 1 shows the comparison of Young's modulus and piezoelectric charge constant between the aligned cellulose EAPap [17] and CEZOHN. Young's modulus of CEZOHN is $5.2 \mathrm{GPa}$, which is almost similar to that of bare cellulose. This result indicates that mechanical rigidity of CEZOHN was not affected by the $\mathrm{ZnO}$ growing. Piezoelectric charge constant $\left(d_{31}\right)$ can be calculated from the induced charge $(Q)$ and force $(F)$ with the following equation [17]:

$$
d_{31}=\frac{Q}{A} \frac{t w}{F}
$$

where $A$ is the electrode area; $t$ and $w$ are the thickness and the width of CEZOHN. Charge $Q$ was found from the measured current. Force $F$ was measured by the load cell installed in the pull test equipment. Piezoelectric charge constant of CEZOHN is found to be $145 \mathrm{pC} / \mathrm{N}$. This result is 30 times larger than the bare cellulose and 6 times than the aligned cellulose [18]. We believe that high piezoelectric charge constant of $\mathrm{CEZOHN}$ is associated with $\mathrm{ZnO}$ nanorods formation on the cellulose film and in-depth study on this phenomenon is on going.

Figure 6. Stress-strain and charge curves of CEZOHN.

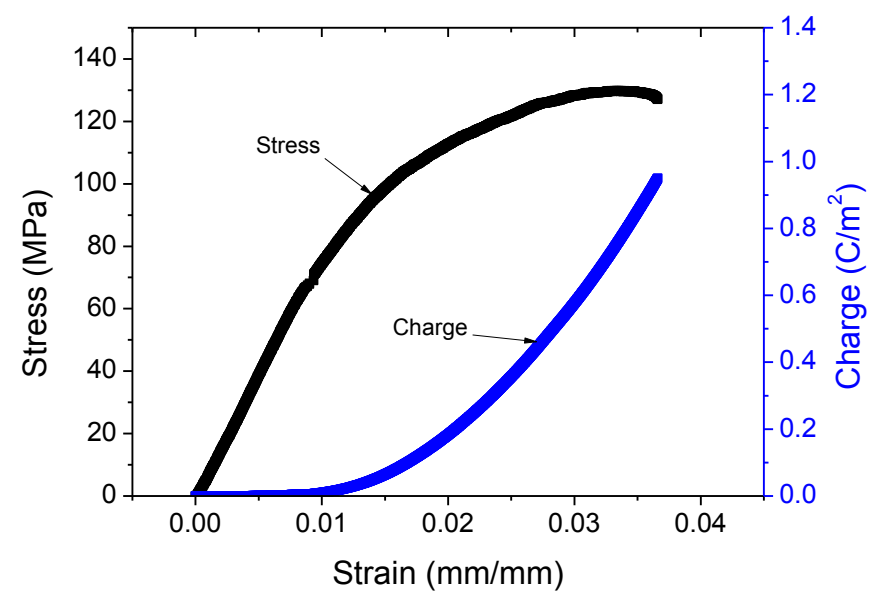


Table 1. Comparison of Young's modulus and piezoelectric charge constant of cellulose and CEZOHN.

\begin{tabular}{ccc}
\hline Samples & Young's modulus $(\mathbf{G P a})$ & Piezoelectric charge constant $\boldsymbol{d}_{\mathbf{3 1}}(\mathbf{p C} / \mathbf{N})$ \\
\hline Bare cellulose & 5.3 & 6 \\
Aligned cellulose & 7.0 & 30 \\
CEZOHN & 5.0 & 145 \\
\hline
\end{tabular}

\subsection{Strain Sensing}

Strain sensing performance of CEZOHN was tested for bending and longitudinal stretching modes. Figure 7 shows the bending displacement at the tip of the cantilever structure and the strain signal under bending mode. When the cantilever beam was tipped $24 \mathrm{~mm}, 3 \mathrm{mV}$ of the bending sensor signal was occurred. The voltage signal and displacement signal show an equivalent free vibration.

Figure 7. Bending mode strain sensor: (a) bending displacement and (b) sensor signal.
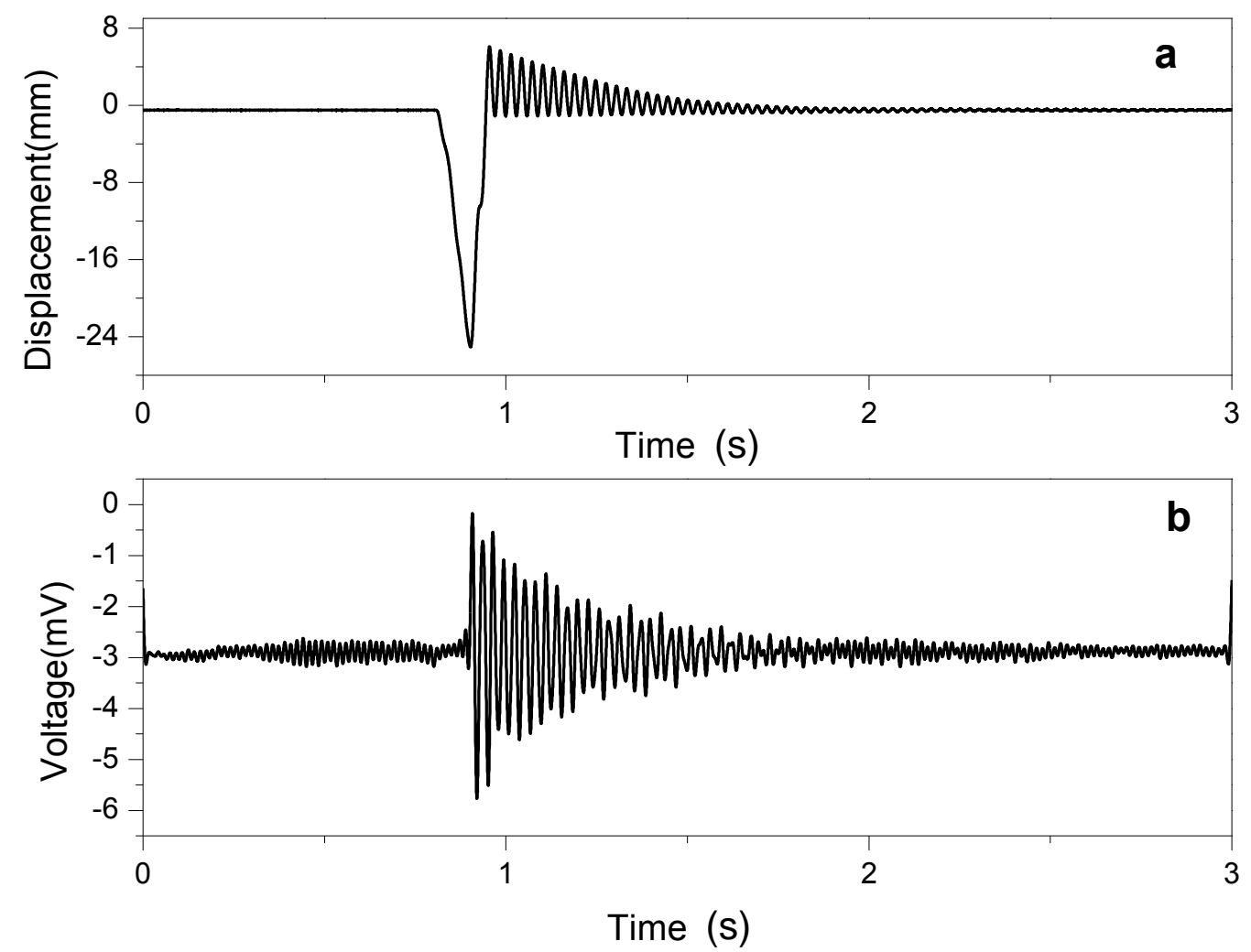

The strain sensor for stretching deformation was tested with the pull test equipment and picoammeter. The applied strain is triangular wave form with $0.8 \times 10^{-3}$ peak to peak strain at $0.05 \mathrm{~Hz}$. Figure 8 shows the strain curve and the sensor signal in current. The sensor signal nearly follows the strain curve. As increasing the strain from zero to $0.8 \mu \mathrm{m} / \mathrm{mm}$, the induced current changed from $40 \mathrm{nA}$ to $-80 \mathrm{nA}$. Sensitivity of the sensor can be found to be $120 \mathrm{nA} / 0.8 \times 10^{-3} \mathrm{~m} / \mathrm{m}=150 \mathrm{nA} /(\mathrm{m} / \mathrm{m})$. From the strain and Young's modulus, stress $\sigma$ is $\mathrm{E} \cdot \varepsilon=5 \mathrm{GPa} \times 0.8 \times 10^{-3}=40 \mathrm{MPa}$. Electrical charge can be found by integrating current. So, the maximum charge $Q$ of the first cycle is $0.5 \times \mathrm{I} \times \mathrm{t}^{2} / \mathrm{A}=0.5 \times 120 \mathrm{nA} \times 10^{2} \mathrm{~s}^{2} / 4 \times 10^{-4} \mathrm{~m}^{2}=15 \mathrm{mC} / \mathrm{m}^{2}$. Thus, the piezoelectric charge constant $d_{31}$ is $\mathrm{Q} / \sigma=375 \mathrm{pC} / \mathrm{N}$. 
Figure 8. Stretching mode strain sensor: (a) stretching strain and (b) sensor signal.
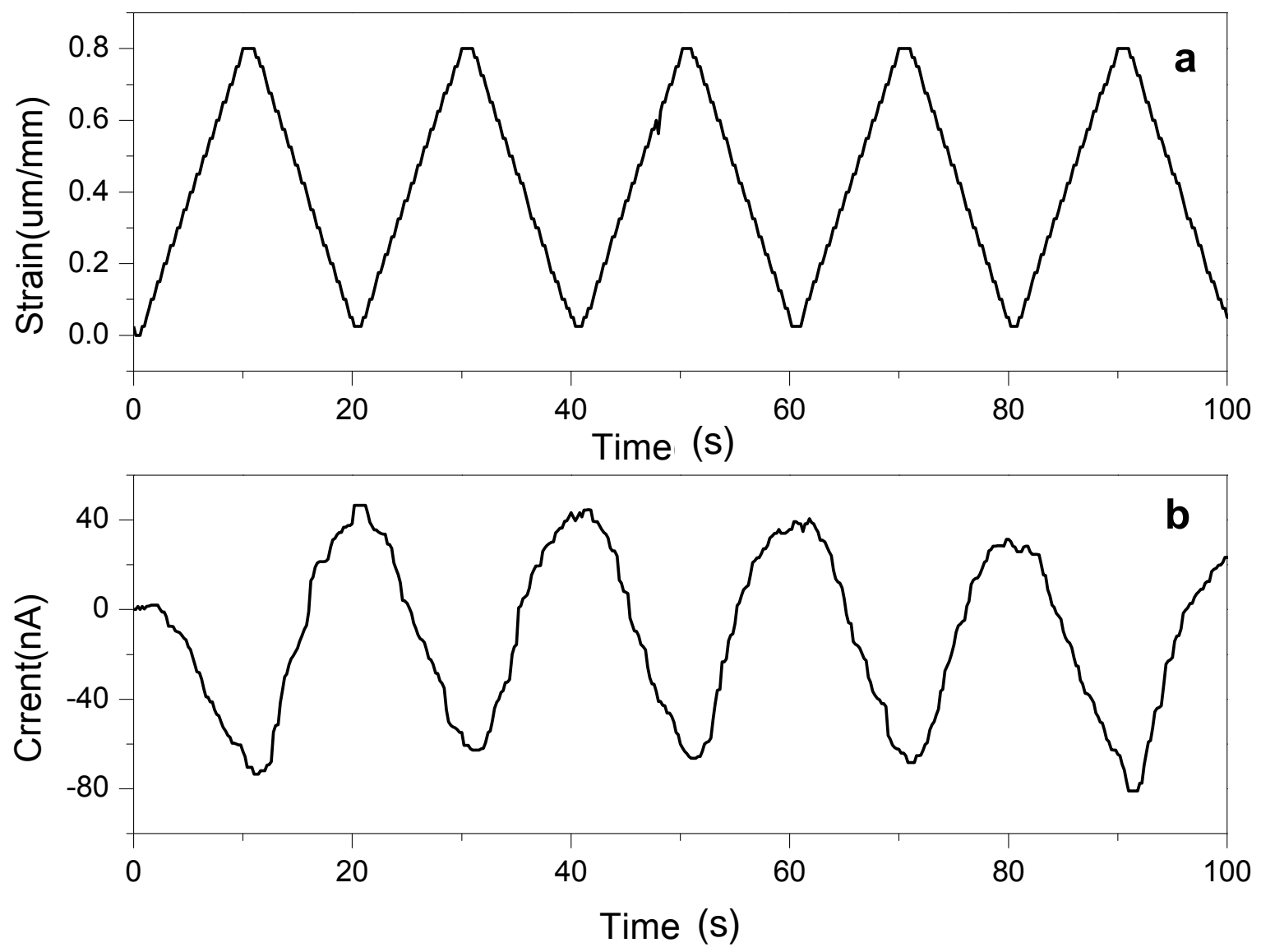

\section{Conclusions}

Well-aligned $\mathrm{ZnO}$ nanorods on cellulose were successfully fabricated by using a low temperature hydrothermal process. Seeding process was introduced for deposition of uniform $\mathrm{ZnO}$ nanorods before growing process. Piezoelectric charge constant of CEZOHN was increased 6 times larger than the aligned cellulose case. When the CEZOHN strain sensor was tested under bending and longitudinal stretching modes, it followed the strain curves. In longitudinal stretching mode, calculated piezoelectric charge constant from the sensor signal was similar to the quasi-static piezoelectric test result.

\section{Acknowledgments}

This research was supported by Basic Science Research Program through the National Research Foundation of Korea (NRF) funded by the Ministry of Education, Science and Technology (NRF-2012R1A2A1A01002087) and Inha Research Fund of Inha University.

\section{Author Contributions}

Hyun-U Ko designed and performed Experiment. Seongcheol Mun performed SEM and EDS studies. Seung-Ki Min performed mechanical and electromechanical test. Ki-Woo Kim advised fabrication process. Jaehwan Kim is responsible for reading this project and entirely edited the manuscript. 


\section{Conflicts of Interest}

The authors declare no conflict of interest.

\section{References}

1. Kim, J.; Yun, S.; Ounaies, Z. Discovery of cellulose as a smart material. Macromolecules 2006, 39, 4202-4206.

2. Yun, S.; Jang, S.; Yun, G.-Y.; Kim, J. Electrically aligned cellulose film for electro-active paper and its piezoelectricity. Smart Mater. Struct. 2009, 18, 117001:1-117001:6.

3. Kim, J.; Yun, G.-Y.; Kim, J.-H.; Lee, J.; Kim, J.-H. Piezoelectric electro active paper (EAPap) speaker. J. Mech. Sci. Technol. 2011, 25, 2763-2768.

4. Kim, J.; Yun, S.; Mahadeva, S.K.; Yun, K.; Yang, S.Y.; Maniruzzaman, M. Paper actuators made with cellulose and hybrid materials. Sensors 2010, 10, 1473-1485.

5. Mun, S.; Chen, Y.; Kim, J. Cellulose-Titanium dioxide-multiwalled carbon nanotube hybrid nanocomposite and its ammonia gas sensing properties at room temperature. Sens. Actuators B Chem. 2012, 171, 1186-1191.

6. Chen, Y.; Mun, S.C.; Kim, J. A wide range conductometric pH sensor made with titanium dioxide/multiwall carbon nanotube/cellulose hybrid nanocomposite. IEEE Sens. J. 2013, 13, 4157-4162.

7. Mahadeva, S.K.; Kim, J. Conductometric glucose biosensor made with cellulose and tin oxide hybrid nanocomposite. Sens. Actuator B Chem. 2011, 157, 177-182.

8. Kim, J.-H.; Yun, S.; Ko, H.-U.; Kim, J. A flexible paper transistor made with aligned single-walled carbon nanotube bonded cellulose composite. Curr. Appl. Phys. 2013, 13, 897-901.

9. Lee, J.; Lee, D.; Lim, D.; Yang, K. Structural, electrical and optical properties of ZnO:Al films deposited on flexible organic substrates for solar cell applications. Thin Solid Films 2007, 515, 6094-6098.

10. Choi, M.-Y.; Choi, D.; Jin, M.-J.; Kim, I.; Kim, S.-H.; Choi, J.-Y.; Lee, S.Y.; Kim, J.M.; Kim, S.-W. Mechanically powered transparent flexible charge-generating nanodevices with piezoelectric ZnO nanorods. Adv. Mater. 2009, 21, 2185-2189.

11. Hao, X.; Ma, J.; Zhang, D.; Yang, T.; Ma, H.; Yang, Y.; Cheng, C.; Huang, J. Thickness dependence of structural, optical and electrical properties of $\mathrm{ZnO}$ :Al films prepared on flexible substrates. Appl. Surf. Sci. 2001, 183, 137-142.

12. Oprea, O.; Aderonescu, E.; Ficai, D.; Ficai, A.; Oktar, F.; Yetmez, M. ZnO applications and challenges. Curr. Org. Chem. 2014, 18, 192-203.

13. Wang, Z.L.; Song, J. Piezoelectric nanogenerators based on zinc oxide nanowire arrays. Science 2006, 312, 242-246.

14. Wang, B.; Kerr, L.L. Dye sensitized solar cells on paper substrates. Solar Energy Mater. Solar Cells 2011, 95, 2531-2535.

15. Gullapalli, H.; Vemuru, V.S.M.; Kumar, A.; Botello-Mendez, A.; Vajtai, R.; Terrones, M.; Nagarajaiah, S.; Ajayan, P.M. Flexible piezoelectric $\mathrm{ZnO}-$ paper nanocomposite strain sensor. Small 2010, 6, 1641-1646. 
16. Ghule, K.; Ghule, A.V.; Chen, B.-J.; Ling, Y.-C. Preparation and characterization of ZnO nanoparticles coated paper and its antibacterial activity study. Green Chem. 2006, 8, 1034-1041.

17. Yun, S.; Kim, J.; Lee, K.-S. Evaluation of cellulose electro-active paper made by tape casting and zone stretching methods. Int. J. Precis. Eng. Manuf. 2010, 11, 987-990.

18. Qu, X.; Jia, D. Synthesis of octahedral ZnO mesoscale superstructures via thermal decomposing octahedral zinc hydroxide precursors. J. Cryst. Growth 2009, 311, 1223-1228.

(C) 2014 by the authors; licensee MDPI, Basel, Switzerland. This article is an open access article distributed under the terms and conditions of the Creative Commons Attribution license (http://creativecommons.org/licenses/by/4.0/). 